\title{
Effectiveness of Psilocybin on Depression: A Qualitative Study
}

\author{
Redhwan Ahmed Al-Naggar ${ }^{1}$, Hisham Alshaikhli ${ }^{*}$, Gwen Erlam ${ }^{2}$
}

\author{
${ }^{1}$ Faculty of Medicine, Al-Hikma University, Sanaa, YEMEN \\ ${ }^{2}$ School of Public Health and Interdisciplinary Studies, Faculty of Health and Environmental Sciences, Auckland University of Technology, Auckland, NEW ZEALAND \\ *Corresponding Author: hishamibrahim69@gmail.com
}

Citation: Al-Naggar RA, Alshaikhli H, Erlam G. Effectiveness of Psilocybin on Depression: A Qualitative Study. Electron J Gen Med. 2021;18(3):em296. https://doi.org/10.29333/ejgm/10862

ARTICLE INFO

Received: 30 Aug. 2020

Accepted: 16 Jan. 2021

\author{
ABSTRACT \\ Introduction: Psilocybin mushroom use is well documented in spiritual and religious ceremonies globally. This \\ drug is now the most popular in Europe and the USA.
}

Objective: The objective of this study is to explore the experiences and effects of psilocybin on patients with depression and anxiety.

Method: A qualitative study was conducted interviewing ten participants currently taking psilocybin while experiencing depression and/or anxiety. Ethical approval was obtained from the University ethics committee. Participants were recruited via social media and groups are known to have used psilocybin for the treatment of anxiety and/or depression. Participants were informed of study aims and consent was obtained before interviews commenced. Confidentiality was maintained throughout this study. Interviews began with informing participants that psilocybin may be effective in the management of depression. Initially, information around the way treatment with psilocybin was obtained was sought. This was followed by queries around the effects of the drug in terms of experiences both during and after treatment. Finally, participants were asked to outline the positive effects of psilocybin on their lives.

Results: The data were thematically coded using Grounded Theory as an underpinning philosophical paradigm. Emerging themes included enhancement of smell, vision, hearing, and taste sensations. Another theme emerging was the experience of being 'connected with the universe' while on the drug. Additionally, participants reported a stabilization of mood, an increase in optimism and emotional control, and a healthier emotional connection with others. Most also felt an increase in comfort, peace and calmness. Another theme that emerged centered on the mechanism of action of psilocybin. Participants stated that this substance seemed to 'make new connections in their brain,' resulting in new perspectives. Some participants felt this resulted in a calming influence on the mind and body. This aligns with research showing that psilocybin works by changing the thinking and improving information processing.

Conclusion: Psilocybin has promising effects on the patients with depression/anxiety even after a single dose. Psilocybin is safe but the administration should be guided by a health professional to yield safe and positive outcomes.

Keywords: Psilocybin, depression, qualitative, mushroom

\section{INTRODUCTION}

Psilocybin is a naturally occurring plant alkaloid that gained the attention of researchers recently as a treatment for several psychiatric disorders [1]. Research regarding psilocybin was first published in the late 1950s [2]. Psilocybin mushrooms have a long history of use in spiritual and religious ceremonies and are now the most popular in Europe and the USA [2-4]. Psilocybin is a structurally diverse group of compounds known as 5-HT2A agonists producing positive effects in emotions, perceptions, and thoughts $[5,6]$. The mechanism of action is similar to all serotonergic psychedelics in that Psilocybin acts as a serotonin 2A receptor (5-HT2AR) agonist [7].

Currently, Psilocybin mushrooms are prohibited in most countries. While these mushrooms can be consumed fresh or dried (with an unpleasant taste), they can also be ingested after dissolved in tea. Mixing in chocolate cream or peanut butter has also been found to make them more palatable. Psilocybin is considered to be one of the least dangerous and the most beneficial drugs in the illicit drug category [8]. Studies have shown that it does not produce any severe mental or physical health effects [9]. Furthermore, several studies have reported that psilocybin produced positive and sustained improvements in overall health and well-being [8]. In fact, enhanced wellbeing was even reported amongst healthy individuals after receiving a single dose of the drug [8]. Therefore, research shows psilocybin can have rapid and lasting positive effects on mental health among those not struggling with depression [10-13].

The positive effects of this drug are well documented as shown by the fact that 80 percent of long-term heavy cigarette smokers demonstrated abstinence from smoking six months following two psilocybin therapy sessions [14]. After one or two 
psilocybin doses, alcohol-addicted patients displayed substantially decreased drinking habits over the next eight months [15]. A study conducted among patients with treatment-resistant depression reported substantial decreases in depressive symptoms one week and three months after 10$25 \mathrm{mg}$ of psilocybin was given in two sessions, seven days apart [16]. Potential effectiveness has also been demonstrated in the treatment of anxiety-related patients suffering terminal diagnoses and obsessive-compulsive disorder [17-20]. There was significant reduction in both depression and anxiety amongst end-stage cancer patients at 3 and 6 months after a single dose of psilocybin [18]. The purpose of this research is to explore the experiences and effects of psilocybin on depression in effected patients.

\section{METHOD}

This study was conducted in March 2019 with the aim of exploring the experiences and effects of psilocybin among depressed patients. Ethical approval was obtained from the University ethics committee. Ten participants were interviewed for this qualitative study. Confidentiality was maintained and informed consent was obtained from all participants. Interview questions were designed based on previous studies and the full questions can be found in the appendices of this article [21].

Participants were recruited through social media and specific groups who have used psilocybin for depression. Inclusion criteria required the participants to be at least 18 years of age. Ten participants responded to invitations to conduct an in-depth interview (approximately 60 minutes) regarding their experience with psilocybin. Interview processes included informing participants that psilocybin may be effective in treating depression; and asking participants to describe details of their experiences during and after receiving this drug. Participants were also asked to describe any positive effects of psilocybin on their day-to-day experience. Information was also sought as to whether the drug was selfadministered or given by a health professional. The interviews were recorded and transcribed. Themes were generated using Grounded Theory as an underpinning philosophical paradigm.

\section{RESULTS}

While participants were informed about the potential effects of psilocybin on depression, most of them learned about these consequences while seeking to treat their own depression. Information was gathered via the internet, social media, and some scientific articles. One participant stated:

I had been curious and was looking for something to help with my depression and suicidal thoughts...I didn't want to die. I couldn't find happiness with my circumstances and pain. I decided to try it out after reading trip reports about how it made them feel whole and like there is something more like God's presence. Participant (2)

Participants reported a variety of physical experiences during and after taking psilocybin. Some reported extreme emotional responses (i.e. laughing followed by crying). One participant experienced giggling, while another described being deeply melancholy. Other experiences included yawning, high temperatures, and enhanced visual changes regarding colors. A common experience amongst participants was nausea and shortness of breath. However, these physical experiences were not all that was reported.

Some participants described more of an existential experience. One stated feeling as if there was an enhanced connection with the universe after taking the drug. Visual and auditory enhancement was reported by participants as below:

I first felt my temperature feel like it went up a little. Then my eyesight started to catch more colors and I remember going to see myself in the mirror. I giggled a lot. My vision got a little distorted, wavy, it seems like things were moving slightly like the room is breathing. I didn't realize [I was] having auditory hallucinations but it was like my mind was a bit drunk so I wasn't processing the information, but it was funny. Participant (2)

It brought back memories of the strong emotions that I have kept inside. There was a flood of positive feelings that came with crying and laughter. Participant (3)

Usually, after 1-2 hours there was an onset of nausea in the tummy and constant yawning. After 1.5 hours the yawning and tired feeling goes away. This can be controlled by taking a small dosage. Participant (5)

In many cases, there is a deep melancholy which you learn to embrace, people call this emptiness. You come to the realization that your entire being is connected with the universe, and that this emptiness is ultimately not empty, but filled. This conclusion alone brings me into a positive realization and out of a depressed state for quite a while. Participant (10)

I began to feel emotionally "dilated". I felt the need to be in the water but also to be alone, so I got in the shower. The shower dial turned into "the eye", the source of knowledge, and I felt energy rising through the stomach and circling breasts like little schools of energy fish. It continued up my chest and got "lodged" in my throat and immediately tears began to stream down my face. I asked the Eye "What is that?" And the Eye said "You know who that is.... that is grief. And you don't need to be afraid of it. Embrace it and make friends with it. Allow it the attention it needs ...." so I cried and cried and cried...and I realized one of the things that were holding me in depression was the inability to properly grieve. Participant (6)

During the session, I felt like my spirit left my body. Participants (7)

Most participants reported clearer thinking after psilocybin was administered. One participant was able to cease taking three anti-depression medications and sleeping pills two weeks after taking psilocybin. Participants also reported some 'mind-expanding' effects which contributed to a more positive outlook on life including a deeper sense of peace and appreciation of self. Others reported enhanced feelings of comfort and understanding along with more frequent meditation and living in the present. Some participants reported mind-expanding effects as below: 
My whole thought pattern changed. I was so relieved. My head had never been clearer. I was so happy the day after I cried to my trip buddy about how I could see again. I felt warm fuzzy and lighter than I did before. I was on three different anti-depressants, valium, and sleeping pills. This stopped within 2 weeks of my first dose. Participant (1)

It is a mind-expanding experience and I felt like it changed my brain. Participant (2)

A deep sense of peace and appreciation for myself and my life. Participant (3)

The session is usually finished after 6 hours. This state I call the afterglow and is the actual state you want to reach since this is the state that most shows you the realization of what utter nonsense your depression is. I feel like I am in complete meditation which means presence, and this state lasts 2-4 days where I feel like I completely know my life's purpose. Participant (5)

Feel comfort, peace, and understanding. I felt incredibly calm and quiet. Participant (6)

The positive effects of Psilocybin seem to involve new connections made in the brain of recipients which subsequently birthed new perspectives. These connections resulted in calming the mind and body. This drug reportedly works by changing the thinking and allowing for more efficient processing of information. Some of the participants said:

I think it works by calming your mind and body, I was never relaxed like that before. I want to say it was my soul getting to know me after years of neglect. Participant (1)

I feel like it has changed my thinking and processing information better and not reacting emotionally. It looks like it was an antivirus for the brain. It rewired my brain. Participant (2)

It enhanced my appreciation for emotions. It works by making new connections in the brain that creates new perspectives. Participant (3)

The frequency of administration was variable. Some participants took 2 doses a month. Others began with an increased initial dose $(8 \mathrm{gm})$ followed by $0.25 \mathrm{gm}$ twice a week. The higher dose was then repeated every three months. Most participants did not exceed a dose of 1.5-2.0 gm at one sitting.

\section{DISCUSSION}

Psilocybin (4-phosphoryloxy-N, N-dimethyltryptamine) is a tryptamine hallucinogen that can be found in psilocybin mushrooms [22]. After oral administration, the onset is between 30 and 60 minutes. Then drug peaks between 90 and 180 minutes with a duration of 6 hours [10]. The effects are dose-dependent and may include visual, cognitive, and emotional alterations that could mimic psychosis [7, 23]. Psilocybin breaks down into psilocin [22, 24]. Psilocin acts as 5$\mathrm{HT}$ agonist and having a high affinity for the 5-HT2A receptor subtype. This receptor is believed to be responsible for the psychotropic effects [5]. Another natural product like ketamine also can rapidly relieve depressive symptoms among depressed patients [25].

The focus here is on the psychological and functional plasticity associated with the acute 'psychedelic' state produced by psilocybin, coupled with the enduring changes that appear to follow from exposure to this drug [1]. Psilocybin has been shown to reduce depression and anxiety along with lessening mood swings [10, 26-32]. A single dose has been found to be more effective in treating anxiety and depression when compared to a placebo [33]. Research has demonstrated a rapid decrease in depressive symptoms when using psilocybin [11, 12, 16-19, 34, 35]. While these studies involved small sample sizes thus limiting generalisability, Muttoni et al. [36] showed Psilocybin produced immediate and significant anti-depressant and anxiolytic effects that lasted for several months. However, the benefits do not stop here.

Participants in another study reported improved quality of life, increased self-confidence, enhanced connections with others, and overall healthier behaviors after psilocybin use [19]. Positive changes in mood and attitudes along with significant improvement in psychological well-being have been observed after this drug was administered $[7,36]$. More than half of participants in some studies considered their psilocybin experience the most significant in their lives [36]. This improvement in the quality of life has been shown to decrease depression and inspire hope in some users.

Concerning the quality of life, $47 \%$ of psilocybin users in one study reported their peak experience in life (Maslow's hierarchy of needs) occurred while using this drug [34]. Other studies have attributed positive changes in attitudes toward self, partners, relationships, and faith, with $80 \%$ of users attributing improvement in life satisfaction to psilocybin. These positive changes were corroborated by participants' colleagues, family, and friends [17]. Psilocybin has been reported to promote continuing positive changes in personality, well-being, and attitude after a single dose [7, 38]. Furthermore, a systematic review reported that micro-dosing of psilocybin can improve attitude, memory, imagination, motivation, transparency, and alteration in time expectations [37].

Results from participants in this study included positive experiences during the administration of psilocybin along with a feeling of being 'connected with the universe.' Participants also reported enhanced color perception in visual fields. Side effects included nausea and shortness of breath. This was in line with previous study findings reporting nausea, abdominal pain, headache, vomiting, physical and psychological discomfort, anxiety, and paranoia could occur with psilocybin use [19, 35, 37].

Further beneficial effects in this study included clearer thinking, cessation of current anti-depressants and sleeping medications, mind-expanding effects, and a more positive outlook on life. Participants also reported a deep sense of peace, comfort, calmness, appreciation for self and life overall. A more focused approach to living included more meditation and living in the present. Participants also reported 'making new connections in the brain,' which resulted in creating new prospective, calming mind and body, and improved processing of information. These factors contributed to what was perceived as a positive move away from past dysfunctional trends [38]. A similar effect was reported by a previous study, which showed that electroconvulsive therapy increased the 
global functional connectivity in the posterior-middle insula, supra-marginal gyrus, and dorsal medial prefrontal cortex [39].

Psilocybin interactions appeared to offer participants enduring, persistent perspectives that contributed to improved self-identity. Participants in this research showed improved personality traits, increased transparency, extraversion, improved conscientiousness, and reduced authoritarian attitudes. A significant increase in tolerance, transparency, confidence, and conscientiousness were also reported. Anhedonia, pessimism, conservative political beliefs, and fear declined. Most participants reported a reduction in neuroticism, and a rise in tolerance contributing to perceptions of redemption, and life acceptance [40] [Shore et al. 2019]. Enhanced spirituality reduced disease-related demoralization and loss of optimism coupled with improved quality of life [1719].

Traditional treatment of depression would include psychotherapy coupled with the use of psilocybin [41]. Oram emphasizes that psychedelic treatment in the absence of a supportive environment and/or psychological support could have limited antidepressant efficacy [42]. Johnson and colleagues agree with the importance of the presence of psychological support [41]. It is therefore essential that all medication administration for depression does not occur in a vacuum.

The pharmacological mechanisms of the neuro-psycho therapeutic effects of psilocybin remain speculative. [5, 43, 44] .The psilocybin metabolite psilocin, as a 5-HT2A agonist, actively and implicitly influences multiple cortical and subcortical brain regions and improves cortical function [4345]. Findings from psilocybin imaging studies show changes in brain activity that indicate antidepressant potential. Several successful antidepressant treatments using intravenous psilocybin have resulted in normalized hyperactivity in the medial prefrontal cortex and reduced blood flow in this area $[43,46]$. Some research has shown psychedelics capable of improving brain-derived neurotrophic factor (BDNF) with resultant positive effects on synaptic plasticity. Psilocybin promotes network disintegration and anti-inflammatory action involving transient bottom-up processes [1, 47]. It also has a neuro-modulatory effect that enhances cognitive reasoning and may contribute to personal intuitions reducing negative thoughts $[43,48]$.

In our study, some participants used 2 doses per month while others administered a larger dose $(8 \mathrm{gm})$ first, then smaller doses $(0.25 \mathrm{gm})$ twice/week followed by a repeat of the larger dose every three months. Griffiths et al [19] reported that a larger dose $(22-30 \mathrm{mg} / 70 \mathrm{~kg}$ ) of psilocybin repeated every five weeks, followed by six-month dosing is effective in treating depression. Other studies $[1,18]$ have shown that a lowmoderate dose of psilocybin $(14 \mathrm{mg} / 70 \mathrm{~kg}$ ) decreased anxiety at one and three months, with subsequent reduction of depression within six months.

Some cancer patients reported that four moderate doses of psilocybin doses $(0.3 \mathrm{mg} / \mathrm{kg})$ in tandem with psychotherapy produced rapid, robust, and enduring anxiolytic, and antidepressant effects [49]. There remains a difference of opinion around the effective dose required. Some studies suggested an initial oral dose of $10 \mathrm{mg}$ followed by an increased dose of $25 \mathrm{mg}$ after one week [16]. Most research seems to consider $30 \mathrm{mg}$ as excessive while $10 \mathrm{mg}$ is sub-therapeutic $[19,50]$.
Concerning the adverse reactions of psilocybin, findings corroborate our and others' previous results fostering the effectiveness and safety of this drug in the management of anxiety and depression [16-19]. Adverse reactions include transient anxiety, transient confusion, thought disorder, mild and transient nausea, dilated pupils, hyper-reflexivity, restlessness, lack of coordination, and temporary headaches [16]. Safety and efficacy remain intact with no significant distress in patients with advanced-stage cancer [18]. Healthy people receiving $30 \mathrm{mg}$ of psilocybin found no sustained physiological or psychological effects [48], and no complications have been reported amongst healthy individuals taking psilocybin [8, 22]. Even in cases of unsupervised and naturalistic conditions, psilocybin has a good safety record and a low-risk profile [51, 52].

\section{LIMITATIONS}

Limitations in this study include a lack of ethnic diversity in participants (only English-speaking participants have been recruited) despite the possibility that the scope of psilocybin use goes beyond English speaking nations and peoples. Another limitation is that this study includes a relatively small number of participants. Further study needs to include larger and more diverse populations. Another limitation is that most of the patients were highly educated which can influence the participants' experiences during and after psilocybin administration.

\section{CONCLUSION}

Psilocybin has promising effects on patients with depression even following a single dose. Psilocybin has proven to be safe when the administration is guided by a health professional and accompanied with psychotherapy.

Author contributions: RAA-N: Designing, planning, collecting the data, writing and data analysis; HA: Writing, proofreading, referencing, prepare for submission, language spelling and grammar correction; GE: Writing, proofreading, editing, preparation for submission, grammatical and spelling correction.

Funding: No funding source is reported for this study.

Declaration of interest: No conflict of interest is declared by authors.

\section{REFERENCES}

1. Carhart-Harris R, Nutt D. Serotonin and brain function: a tale of two receptors. Journal of Psychopharmacology, 2017;31(9):1091-120. https://doi.org/10.1177/0269881117 725915 PMid:28858536 PMCid:PMC5606297

2. Hofmann A, Heim R, Brack A, Kobel H. Psilocybin, a psychotropic substance from the Mexican mushroom Psilicybe mexicana Heim. Experientia, 1958;14(3):107. https://doi.org/10.1007/BF02159243 PMid:13537892

3. Germann CB. The Psilocybin-Telomere Hypothesis: An empirically falsifiable prediction concerning the beneficial neuropsychopharmacological effects of psilocybin on genetic aging. Medical hypotheses, 2020;134:109406. https://doi.org/10.1016/j.mehy.2019.109406 PMid:31634774 
4. Germann CB. 5-methoxy-N, N-dimethyltryptamine: An egodissolving endogenous neurochemical catalyst of creativity. Activitas Nervosa Superior, 2019;61(4):170-216. https://doi.org/10.1007/s41470-019-00063-y

5. Nichols DE. Psychedelics. Pharmacological reviews, 2016;68(2):264-355. https://doi.org/10.1124/pr.115.011478 PMid:26841800 PMCid:PMC4813425

6. Halberstadt AL. Recent advances in the neuropsychopharmacology of serotonergic hallucinogens. Behavioural brain research, 2015;277:99-120. https://doi.org/10.1016/j.bbr.2014.07.016 PMid:25036425 PMCid:PMC4642895

7. Vollenweider FX, Vollenweider-Scherpenhuyzen MFI, Bäbler A, Vogel H, Hell D. Psilocybin induces schizophrenialike psychosis in humans via a serotonin-2 agonist action. Neuroreport, 1998;9(17):3897-902. https://doi.org/10.1097 /00001756-199812010-00024 PMid:9875725

8. Van Amsterdam J. Opperhuizen A, van den Brink W. Harm potential of magic mushroom use: a review. Regulatory toxicology and pharmacology, 2011;59(3):423-9. https:// doi.org/10.1016/j.yrtph.2011.01.006 PMid:21256914

9. Krebs TS, Johansen P- $\varnothing$. Lysergic acid diethylamide (LSD) for alcoholism: meta-analysis of randomized controlled trials. Journal of Psychopharmacology, 2012;26(7):9941002. https://doi.org/10.1177/0269881112439253 PMid: 22406913

10. Griffiths RR, Johnson MW, Richards WA, Richard BD, McCann U, Jesse R. Psilocybin occasioned mystical-type experiences: immediate and persisting dose-related effects. Psychopharmacology, 2011;218(4):649-65. https://doi.org/10.1007/s00213-011-2358-5 PMid:21674151 PMCid:PMC3308357

11. Gasser P, Holstein D, Michel Y, Doblin R, Yazar-Klosinski B, Passie T, Brenneisen R. Safety and efficacy of lysergic acid diethylamide-assisted psychotherapy for anxiety associated with life-threatening diseases. The Journal of nervous and mental disease, 2014;202(7):513. https://doi.org/10.1097/NMD.0000000000000113 PMid:24594678 PMCid:PMC4086777

12. Sanches RF, de Lima Osório F, dos Santos R, Macedo LRH, Maia-de-Oliveira JP, et al. Antidepressant effects of a single dose of ayahuasca in patients with recurrent depression: a SPECT study. Journal of clinical psychopharmacology, 2016;36(1):77-81. https://doi.org/10.1097/JCP.0000000000 000436 PMid:26650973

13. Osório FdL, Sanches RF, Macedo LR, dos Santos RG, Maiade-Oliveira JP, et al. Antidepressant effects of a single dose of ayahuasca in patients with recurrent depression: a preliminary report. Brazilian Journal of Psychiatry, 2015;37(1):13-20. https://doi.org/10.1590/1516-4446-20141496 PMid:25806551

14. Johnson MW, Garcia-Romeu A, Cosimano MP, Griffiths RR. Pilot study of the 5-HT2AR agonist psilocybin in the treatment of tobacco addiction. Journal of psychopharmacology, 2014;28(11):983-92. https://doi.org/ 10.1177/0269881114548296 PMid:25213996 PMCid: PMC4286320

15. Bogenschutz MP, Forcehimes AA, Pommy JA, Wilcox CE, Barbosa PCR, Strassman RJ. Psilocybin-assisted treatment for alcohol dependence: a proof-of-concept study. Journal of psychopharmacology, 2015;29(3):289-99. https://doi.org /10.1177/0269881114565144 PMid:25586396
16. CarhartHarris RL, Kaelen M, Bolstridge M, Williams TM, Williams LT, Underwood R, Feilding A, Nutt DJ. The paradoxical psychological effects of lysergic acid diethylamide (LSD). Psychological medicine, 2016;46(7):1379-90. https://doi.org/10.1017/S00332917150 02901 PMid:26847689

17. Ross S, Bossis A, Guss J, Agin-Liebes G, Malone T, et al. Rapid and sustained symptom reduction following psilocybin treatment for anxiety and depression in patients with life-threatening cancer: a randomized controlled trial. Journal of psychopharmacology, 2016;30(12):1165-80. https://doi.org/10.1177/0269881116675512

PMid:27909164 PMCid:PMC5367551

18. Grob CS, Danford AL, Chopra GS, Hagerty M, McKay CR, et al. Pilot study of psilocybin treatment for anxiety in patients with advanced-stage cancer. Archives of general psychiatry, 2011;68(1):71-8. https://doi.org/10.1001/ archgenpsychiatry.2010.116 PMid:20819978

19. Griffiths RR, Johnson MW, Carducci MA, Umbricht A, Richards WA, et al. Psilocybin produces substantial and sustained decreases in depression and anxiety in patients with life-threatening cancer: A randomized double-blind trial. Journal of psychopharmacology, 2016;30(12):118197. https://doi.org/10.1177/0269881116675513 PMid: 27909165 PMCid:PMC5367557

20. Moreno FA, Wiegand CB, Keolani Taitano E, Delgado PL. Safety, tolerability, and efficacy of psilocybin in 9 patients with obsessive-compulsive disorder. Journal of Clinical Psychiatry, 2006;67(11):1735-40. https://doi.org/10.4088/ JCP.v67n1110 PMid:17196053

21. Belser AB, Agin-Liebes G, Swift C, Terrana S, et al. Patient experiences of psilocybin-assisted psychotherapy: an interpretative phenomenological analysis. Journal of Humanistic Psychology, 2017;57(4):354-88. https://doi.org/10.1177/0022167817706884

22. Passie T, Seifert J, Schneider U, Emrich HM. The pharmacology of psilocybin. Addiction biology, 2002;7(4):357-64. https://doi.org/10.1080/1355621021000 005937 PMid: 14578010

23. Studerus E, Kometer M, Hasler F, Vollenweider FX. Acute, subacute and long-term subjective effects of psilocybin in healthy humans: a pooled analysis of experimental studies. Journal of psychopharmacology, 2011;25(11):1434-52. https://doi.org/10.1177/0269881110382466 PMid:20855349

24. Brown RT, Nicholas CR, Cozzi NV, Gassman MC, Cooper KM, et al. Pharmacokinetics of escalating doses of oral psilocybin in healthy adults. Clinical pharmacokinetics, 2017;56(12):1543-54. https://doi.org/10.1007/s40262-0170540-6 PMid:28353056

25. Zhuo C, Ji F, Tian H, Wang L, Jia F, et al. Transient effects of multi - infusion ketamine augmentation on treatment resistant depressive symptoms in patients with treatment - resistant bipolar depression - An open - label three - week pilot study. Brain and Behavior, 2020;10(8):e01674. https://doi.org/10.1002/brb3.1674

26. Farzin D, Mansouri N. Antidepressant-like effect of harmane and other $\beta$-carbolines in the mouse forced swim test. European neuropsychopharmacology, 2006;16(5):324-8. https://doi.org/10.1016/j.euroneuro.2005.08.005 PMid:16183262 
27. Fortunato JJ, Reus GZ, Kirsch TR, Stringari RB, Fries GR, Kapczinki $F$, et al. Effects of $\beta$-carboline harmine on behavioral and physiological parameters observed in the chronic mild stress model: Further evidence of antidepressant properties. Brain research bulletin, 2010;81(4-5):491-6. https://doi.org/10.1016/j.brainresbull. 2009.09.008 PMid:19772900

28. Santos RG, Landeira-Fernandez J, Strassman RJ, Cruz APM. Effects of ayahuasca on psychometric measures of anxiety, panic-like and hopelessness in Santo Daime members. Journal of ethnopharmacology, 2007;112(3):507-13. https://doi.org/10.1016/j.jep.2007.04.012 PMid:17532158

29. Fortunato JJ, Reus GZ, Kirsch TR, Stringari RB, Stertz L, et al. Acute harmine administration induces antidepressivelike effects and increases BDNF levels in the rat hippocampus. Progress in Neuro-Psychopharmacology and Biological Psychiatry, 2009;33(8):1425-30. https://doi. org/10.1016/j.pnpbp.2009.07.021 PMid:19632287

30. Hilber P, Chapillon P. Effects of harmaline on anxietyrelated behavior in mice. Physiology \& behavior, 2005;86(12):164-7. https://doi.org/10.1016/j.physbeh.2005.07.006 PMid:16112150

31. Riba J, Rodriguez-Fornells A, Urbano G, Morte A, Antonijoan $R$, et al. Subjective effects and tolerability of the South American psychoactive beverage Ayahuasca in healthy volunteers. Psychopharmacology, 2001;154(1):85-95. https://doi.org/10.1007/s002130000606 PMid:11292011

32. Griffiths RR, Richards WA, Johnson MW, McCann UD, Jesse R. Mystical-type experiences occasioned by psilocybin mediate the attribution of personal meaning and spiritual significance 14 months later. Journal of psychopharmacology, 2008;22(6):621-32. https://doi.org/ 10.1177/0269881108094300 PMid:18593735 PMCid: PMC3050654

33. Ostuzzi G, Matcham F, Dauchy S, Barbui C, Hotopf M. Antidepressants for the treatment of depression in people with cancer. Cochrane Database of Systematic Reviews, 2018;(4). https://doi.org/10.1002/14651858.CD011006. pub3 PMid:29683474 PMCid:PMC6494588

34. Palhano-Fontes F, Barreto D, Onias H, Andrade KC, Novaes MM, Pessoa JA, et al. Rapid antidepressant effects of the psychedelic ayahuasca in treatment-resistant depression: a randomized placebo-controlled trial. Psychological medicine, 2019;49(4):655-63. https://doi.org/10.1017/ S0033291718001356 PMid:29903051 PMCid:PMC6378413

35. Carhart-Harris RL. Serotonin, psychedelics and psychiatry. World Psychiatry, 2018;17(3):358. https://doi.org/ 10.1002/wps.20555 PMid:30192100 PMCid:PMC6127802

36. Muttoni S, Ardissino M, John C. Classical psychedelics for the treatment of depression and anxiety: a systematic review. Journal of affective disorders, 2019;258:11-24. https://doi.org/10.1016/j.jad.2019.07.076 PMid:31382100

37. Barbosa PCR, Mizumoto S, Bogenschutz MP, Strassman RJ. Health status of ayahuasca users. Drug testing and analysis, 2012;4(7-8):601-9. https://doi.org/10.1002/ dta.1383 PMid:22761152

38. Nichols DE, Johnson MW, Nichols CD. Psychedelics as medicines: an emerging new paradigm. Clinical Pharmacology \& Therapeutics, 2017;101(2):209-19. https://doi.org/10.1002/cpt.557 PMid:28019026
39. Li X, Meng H, Fu Y, Du L, Qiu H, et al. The impact of whole brain global functional connectivity density following MECT in major depression: a follow-up study. Frontiers in psychiatry, 2019;10:7. https://doi.org/10.3389/fpsyt. 2019.00007 PMid:30890964 PMCid:PMC6413803

40. Shore RJ, Loudovski P, McKeown S, Dumont E, Goldie C. Mapping Psilocybin-Assisted Therapies: A Scoping Review. medRxiv, 2019. https://doi.org/10.1101/2019.12.04. 19013896

41. Johnson MW, Richards WA, Griffiths RR. Human hallucinogen research: guidelines for safety. Journal of psychopharmacology, 2008;22(6):603-20. https://doi.org/ 10.1177/0269881108093587 PMid:18593734 PMCid: PMC3056407

42. Oram M. Efficacy and enlightenment: LSD psychotherapy and the drug amendments of 1962. Journal of the History of Medicine and Allied Sciences, 2014;69(2):221-50. https://doi.org/10.1093/jhmas/jrs050 PMid:22898355

43. Carhart-Harris RL, Erritzoe D, Williams T, Stone JM, Reed LJ, Colasanti A, et al. Neural correlates of the psychedelic state as determined by $\mathrm{fMRI}$ studies with psilocybin. Proceedings of the National Academy of Sciences, 2012;109(6):2138-43. https://doi.org/10.1073/pnas.1119598109 PMid:22308440 PMCid:PMC3277566

44. Vollenweider FX, Kometer $M$. The neurobiology of psychedelic drugs: implications for the treatment of mood disorders. Nature Reviews Neuroscience, 2010;11(9):642. https://doi.org/10.1038/nrn2884

45. Carhart-Harris RL, Leech R, Hellyer PJ, Shanahan M, Feilding A, et al. The entropic brain: a theory of conscious states informed by neuroimaging research with psychedelic drugs. Frontiers in human neuroscience, 2014;8:20. https://doi.org/10.3389/fnhum.2014.00020 PMid:24550805 PMCid:PMC3909994

46. Ly C, Greb AC, Cameron LP, Wong JM, Barragan EV, et al. Psychedelics promote structural and functional neural plasticity. Cell reports, 2018;23(11):3170-82. https://doi.org/10.1016/j.celrep.2018.05.022

PMid:29898390 PMCid:PMC6082376

47. Flanagan TW, Nichols CD. Psychedelics as antiinflammatory agents. International Review of Psychiatry, 2018;30(4):363-75. https://doi.org/10.1080/09540261.2018. 1481827 PMid:30102081

48. Griffiths RR, Richards WA, McCann U, Jesse R. Psilocybin can occasion mystical-type experiences having substantial and sustained personal meaning and spiritual significance. Psychopharmacology, 2006;187(3):268-83. https://doi.org/ 10.1007/s00213-006-0457-5 PMid:16826400

49. Malone TC, Mennenga SE, Guss J, Podrebarac SK, Owens $\mathrm{LT}$, et al. Individual experiences in four cancer patients following psilocybin-assisted psychotherapy. Frontiers in pharmacology, 2018;9:256. https://doi.org/10.3389/ fphar.2018.00256 PMid:29666578 PMCid:PMC5891594

50. Carhart-Harris R, Bolstridge M, Day CMJ, Rucker J, Watts R, et al. Psilocybin with psychological support for treatmentresistant depression: six-month follow-up. Psychopharmacology, 2018;235(2):399-408. https://doi.org /10.1007/s00213-017-4771-x PMid:29119217 PMCid: PMC5813086

51. Nutt DJ, King LA, Phillips LD. Drug harms in the UK: a multicriteria decision analysis. The Lancet, 2010;376(9752):1558-65. https://doi.org/10.1016/S01406736(10)61462-6 
52. Schenberg EE, Alexandre JFM, Filev R, Cravo AM, Sato JR, et al. Acute biphasic effects of ayahuasca. PloS one, 2015;10(9):e0137202. https://doi.org/10.1371/journal.pone .0137202 PMid:26421727 PMCid:PMC4589238 